\title{
Evolution of a field: Swiss media and communication studies
}

\author{
Carole Probst, Zurich University of Applied Sciences ZHAW, Winterthur, Switzerland* \\ Alexander Buhmann, BI Norwegian Business School, Department of Communication and Culture, \\ Oslo, Norway \\ Diana Ingenhoff, University of Fribourg, DCM Department of Communication and Media Research, \\ Switzerland \\ Benedetto Lepori, Università della Svizzera italiana, Facoltà di scienze della comunicazione, \\ Lugano, Switzerland \\ ${ }^{*}$ Corresponding author: carole.probstschilter@zhaw.ch
}

\begin{abstract}
In this paper, we present the evolution of Swiss Media and Communication Studies over the last decade by summarizing the main results from a project funded by the Swiss University Conference (2008-2017). We give an overall picture of the growth in the field (in terms of student numbers, resources and activities), look at diversity in terms of topics (two clusters are identified and presented with respect to various indicators), present changes at the level of individual research units (where we find variance in terms of evolution), give insights into publication patterns (two different publication cultures are found) and describe mobility and career pathways in the field. We observe limited mobility within Switzerland, internal pathways at the level of doctoral students and post-docs, and international mobility, mainly within the same linguistic region, at the professorial level. We conclude that the field has reached a consolidation phase and achieved a rather stable situation, but faces new challenges, with digitalization and the pressure towards homogenization in publication output among the most important.
\end{abstract}

\section{Keywords}

media studies, communication studies, Switzerland, publication cultures

\section{Introduction}

Understanding the structure and evolution over time of a scientific field is relevant for numerous actors in research policy and within the science system. Policymakers and university managers might want to better understand the scientific output of the field (Hicks, Wouters, Waltman, De Rijcke, \& Rafols 2015) and the societal relevance of its research (Hessels \& Freeman, 2010), helping them to target financial efforts to the most relevant domains; scholars might be more interested in understanding which research topics are emerging and are being institutionalized in order to orient their research agenda (Latour \& Woolgar, 1979), while young scientists will be concerned predominantly by the changing structure of academic careers and by the opportunities available for stable jobs (Enders \& Musselin, 2008).
In this article, we focus specifically on the state and development of the field of Media and Communications Studies (MCS) in Switzerland.

It is well known that there is a broad debate on the characteristics of the field, both internationally (Altmeppen, Weigel, \& Gebhard, 2011; Corner, 2013) and in the Swiss context (Saxer, 2007). Regarding Switzerland, the field has also witnessed a rapid growth in terms of institutionalization, educational offers and student numbers since the mid-1990s (Meier \& Blum, 2004; Gysin, Meier, Blum, Häussler, \& Süss, 2004; Schade, 2005).

Our study aims to explore these developments in more depth by addressing several related questions: To what extent is this growth reflected in dimensions such as personnel, research funds and publication output? Is the overall evolution reflected in the individual research units? 
Many researchers in the field might consider themselves part of a sub-community of MCS, as the field covers a wide range of topics. What differences do we observe between units in terms of topical orientation and activity profiles? To what extent does this orientation in terms of topics influence the activities and resources of individual research units?

In their daily work or when looking at colleagues, researchers in the field notice pressure for more publication in international journals. Is this a common expectation in the field of MCS, and are international journal publications really the gold standard? Also, are specific subfields more susceptible to this pressure?

Furthermore, such pressures may vary significantly for senior, mid-level, and junior researchers depending on their embedding in the career structure-specifically considering the steep hierarchies, small number of professors with stable positions at the top (often hired from abroad) and overabundance of postdoctoral researchers with insecure positions at the bottom, which is common to Swiss academia (SBFI, 2014). But, looking at MCS specifically: Are there typical career pathways that can be identified? Where do people in the field come from, and where are they going to?

These are questions we address in this article. In order to do so, we summarize the main results from two projects funded by the Swiss University Conference in the years 2008-2011 and 2013-2017 respectively, as part of a national program measuring research performance in the humanities and social sciences. Specifically, the projects aimed to map and characterize the complex, multidisciplinary field of MCS in Switzerland and to develop indicators for measuring its research output, taking into consideration the heterogeneity of topics and activities.

Our research shows that, similarly to other countries, in terms of their total activities Swiss MCS have seen a rapid development starting in the 1990s (see section 3 , below). In addition, topical diversity and different sub-communities can be observed (section 4). With the results of our studies, we are able to offer an in-depth analysis of the overall development over the last decade. We thus look at how individual units differ in terms of their activity profiles and their development over time (section 5), with a focus on publications (section 6) and on career structures (section 7).

Our analysis therefore depicts the complexity of evolution in the field, which lies at the crossroads between the pressure of global standards regarding international publication activities and careers, societal needs for education and relevance of research and, finally, the lasting cultural and disciplinary differences within the field. The complexities and struggles we describe are likely to have a deep impact on our scholarly activities in the future.

\section{Measuring research units through their activities: Methodology and data}

Our project focused on evaluating the field of communication science and media research and was developed in close collaboration with the Swiss Association of Communication and Media Research (SACMR). Our central units of analysis are research units. We define these as "organized groups of researchers that are officially recognized by the higher education institution (e.g., institutes, departments, or chairs), display some level of internal organization and are responsible for managing their own budget" (Buhmann, Ingenhoff, \& Lepori, 2015, p. 271, see also Lepori et al., 2011; Larédo \& Mustar, 2000).

Indicators. Measuring activities, such as those in research, teaching and industry transfer, in the diverse field of social sciences and humanities, requires an approach that goes beyond publication lists and funding. We therefore opted for "activity profiles", a multi-dimensional approach respecting the multi-activity and multi-product nature of research units (Larédo \& Mustar, 2000; van Vught, 2009; Schmoch, Schubert, Jansen, Heidler, \& von Görtz, 2010; Braam \& van den Besselaar, 2010). In order to produce a balanced 
Table 1: Dimensions and indicators for mapping Swiss MCS

\begin{tabular}{|c|c|}
\hline Dimension & Indicators \\
\hline Subject topics* & $\begin{array}{l}\text { A comprehensive list of MCS research topics derived from the topics mentioned in the so-called Swiss } \\
\text { KMW Atlas, }{ }^{a} \text { as well as from the common divisions and working groups within the ICA and DGPUK. Heads of } \\
\text { units were asked to indicate their importance for their unit using a three-point scale. }\end{array}$ \\
\hline \multirow[t]{2}{*}{$\begin{array}{l}\text { Education and } \\
\text { transfer activities }\end{array}$} & $\begin{array}{l}\text { Educational activities**: For each level (bachelor, master, and continuing education), number of hours orga- } \\
\text { nized, number of hours taught, number of supervised theses }\end{array}$ \\
\hline & Public and private sector transfer*: Board memberships, research reports, presentations, funds ${ }^{* *}$ \\
\hline \multirow[t]{3}{*}{ Scientific production } & $\begin{array}{l}\text { Scientific output**: Number of publications (differentiated by outlet: articles, book chapters, monographs, } \\
\text { edited books), language of publication, number of conference presentations }\end{array}$ \\
\hline & $\begin{array}{l}\text { Community recognition*: Keynote speeches, edited special issues, executive board memberships in scholarly } \\
\text { associations, advisory board memberships in scholarly journals, research grants from agencies supporting } \\
\text { basic research }\end{array}$ \\
\hline & $\begin{array}{l}\text { Research training**: Number of } \mathrm{PhD} \text { students, organized } \mathrm{PhD} \text { courses, finished } \mathrm{PhD} \text { theses, number of } \mathrm{PhD} \\
\text { publications, conferences, and duration of } \mathrm{PhD} \text { studies abroad }\end{array}$ \\
\hline \multirow[t]{3}{*}{ Resources } & Size ${ }^{* *}:$ Total number of full-time equivalent positions (FTE) \\
\hline & Composition of personnel**: External vs. internal personnel; PhDs, post-docs, professors \\
\hline & Acquired funding ${ }^{* *}$ : Total of acquired funds in Swiss Francs (CHF) \\
\hline
\end{tabular}

Source. Swiss Federal Statistical Office (data in the field "Kommunikations- und Medienwissenschaft» (universities) and "Kommunikation» (universities of applied sciences). ahttps://sgkm.ch/en/about-us/kmw-atlas (21.02.2019). * data for 2009, ${ }^{* *}$ data for 2009-2013.

picture of the various activities and outcomes, we derived four main dimensions and operationalized them using a wide range of indicators (see Table 1).

Institutional units. In general, we consider units that are institutionally recognized, but are sufficiently coherent in terms of topics, like chairs or institutes; faculties (at USI Lugano) and departments (in Zurich and Fribourg) are therefore divided into sub-units. In German-speaking universities this frequently corresponds to the chair level (professor plus research group), while in universities like USI it corresponds to the institute level (with several professors sharing topics and resources).

Sample and timeframe. Two data collections have been undertaken with different timeframes and slightly different samples and indicators.

Data collection 1 refers to the year 2009 (2005-2009 for scientific publications) and covers 22 research units including all units in Bern, Fribourg, Lugano, Neuchâtel and St. Gallen, as well as most of the units in Zurich; among the universities listed in the Swiss KMW Atlas ${ }^{1}$, only Basel and Geneva are missing from our sample. In contrast, the sample is far from representative for

$1 \mathrm{https} / / \mathrm{sgkm} . \mathrm{ch} / \mathrm{en} / \mathrm{about}-\mathrm{us} / \mathrm{kmw}$-atlas (21.02.2019) universities of applied sciences, where only one unit among the seven listed in the SACMR KMW Atlas is included. All indicators listed in Table 1 were collected.

Data collection 2 refers to the years 2009-2013 and therefore provides a longitudinal view of the evolution of the field. The sample was composed of 22 units; compared with the first sample, only two units in Zurich are included, but the Department of Communication in Fribourg was split to provide a more precise analysis. The units' data were mostly quantitative, such as educational volume, students, degrees, staff and funding.

These data also include a detailed analysis of the careers of people working at these units for the period 2009-2013 that allows an in-depth analysis of recruitment and career paths in the field.

Finally, we turn to the Swiss Federal Statistical Office for the number of students in the field of communication and media for the whole period from 1981 to 2016 , in order to provide a longer perspective on the evolution of the field.

While our main data do not go beyond 2013, we argue below that they concern a period following the big wave of expansion of the field in the late 1990s and early 2000s and, therefore, can be considered as fairly 
representative of the current situation. An update to inform on more recent developments would, however, be interesting.

Data sources. Data were collected from a wide variety of sources: Websites, CVs, and self-maintained web profiles of researchers (published on the internet or social networks such as LinkedIn, ResearchGate and Xing), survey questionnaires (first phase only) to staff members and heads of research units, publication lists, and course books.

For more in-depth discussions and detailed information on the project and on the construction of the instrument, please refer to previous articles of the authors (Probst, Lepori, \& Ingenhoff, 2010; Probst, Lepori, De Filippo, \& Ingenhoff, 2011; Lepori et al., 2011; Lepori, Probst, \& Ingenhoff, 2012; Buhmann et al., 2015; Wise, Lepori, Ingenhoff, \& Buhmann, 2015; Lepori, Wise, Ingenhoff, \& Buhmann, 2016; Buhmann, Lepori, \& Ingenhoff, 2017).

\section{The overall evolution in terms of resources and activities}

\subsection{The field's institutional evolution}

In Switzerland, even though the first courses in journalism were taught at the universities of Zurich and Fribourg at the beginning of the last century (Gysin et al., 2004), until the mid-1990s, the field was only weakly institutionalized and had just a few professors mainly in Fribourg and Zurich (Bonfadelli, 2007).

The development of the field started in the 1990s and involved different processes: the creation of units within departments of social sciences explicitly oriented towards communication, the creation of dedicated curricula in communication (as self-standing curricula or as a specialization within broader curricula in social sciences and humanities) and, starting around 2000, the expansion of MCS also to the newly created universities of applied sciences (Lepori, 2008).

From the mid-1990s, the educational offer in Zurich was expanded, while new curricula or institutes in communication were opened at the universities of Basel (1995), St. Gallen (1998), Geneva (1999) and Lucerne (2002). In 1996, the Faculty of Communication Sciences at the Università della Svizzera italiana (USI) in Lugano opened its doors to the first students. By 2000, five different places already offered the possibility to study MCS (Süss, 2000). Since then, the evolution of the field has been more gradual.

The evolution of student numbers illustrates this development. Data from the Swiss Federal Statistical Office (SFSO) presented in Figure 1 need to be read with care since they include only students enrolled in curricula explicitly labelled as communication, and exclude educational offerings within other curricula, like in Bern and St. Gallen, as well as expanding offerings at the master's level and in postgraduate education; nevertheless, they provide a useful temporal picture.

We first observe that before 1996 only Fribourg offered a minor in communication. A rapid increase in the number of students started in 1996 with the new educational offerings at the University of Zurich and at USI in Lugano. The peak between 2001 and 2002 can probably be explained by the unmet demand of previous years when suitable education offers were lacking in the field. After a slight drop from this peak, from 2004 onwards student numbers steadily increased for a decade. Starting in 2014, the number of new enrolments started to decrease in all universities, possibly pointing to a loss of attractiveness of the field.

\subsection{A more fine-grained view for the period 2009-2013}

Our data provide a more fine-grained view of the field's activities and of their evolution, albeit for a rather short period of time.

As shown in Table 2, during the period from 2009 to 2013, which was rather stable in terms of student numbers, we see an increase in total full-time equivalent positions (FTE) of $22 \%$, which is stronger at the professorial $(+25 \%)$ and senior $(+22 \%)$ levels than at the junior level $(+15 \%)$. This increase can be interpreted as a sort of 
Figure 1: Students starting their bachelor's degree at Swiss Universities and Universities of Applied Sciences

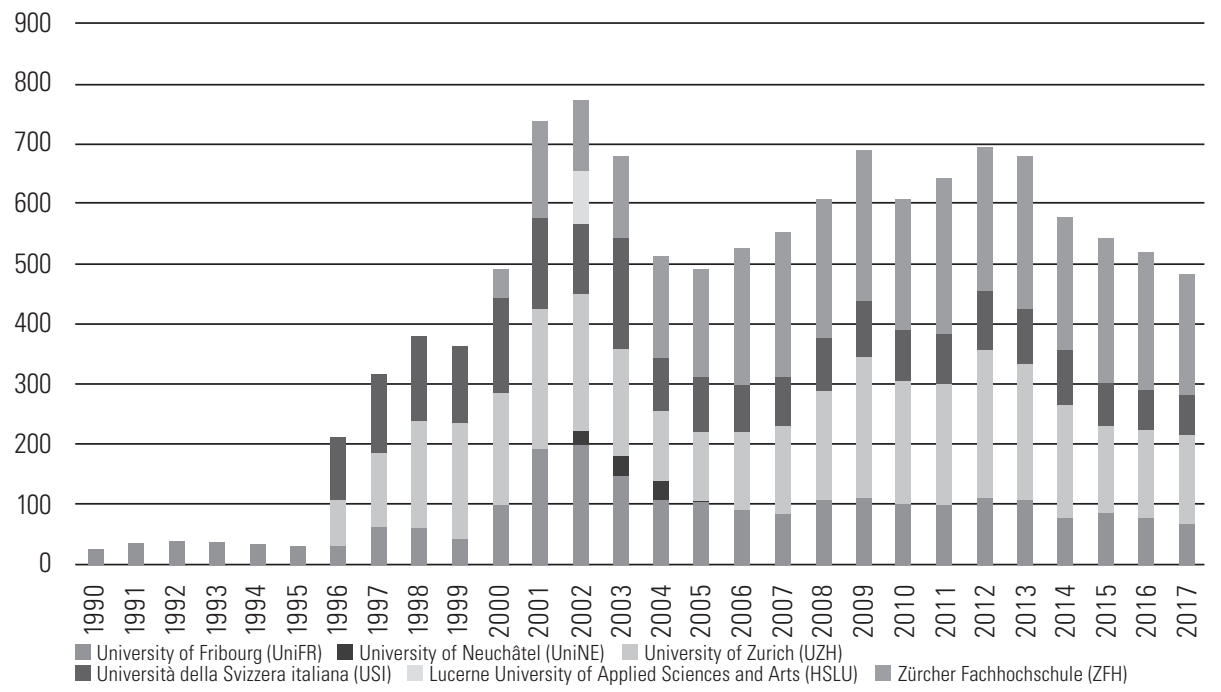

Table 2: $\quad$ Time evolution of selected indicators

\begin{tabular}{lccccc}
\hline & 2009 & 2010 & 2011 & 2012 & 2013 \\
\hline Total FTE & 113.86 & 122.94 & 127.55 & 130.75 & 138.42 \\
Professorial FTE & 27.91 & 30.11 & 31.68 & 31.76 & 35.02 \\
Senior FTE & 39.1 & 42.48 & 45.74 & 47.09 & 49.48 \\
Junior FTE & 46.85 & 50.14 & 50.13 & 51.9 & 53.92 \\
Third-party funds & 4052298 & 3871500 & 3446317 & 4759047 & 4640299 \\
Publications & 231 & 161 & 151 & 182 & 215 \\
BA students enrolled & 585 & 579 & 581 & 593 & 568 \\
MA students enrolled & 381 & 413 & 420 & 385 & 387 \\
PhD students & 62 & 67 & 80 & 76 & 84 \\
BA theses supervised & 236 & 209 & 255 & 234 & 270 \\
MA theses supervised & 84 & 116 & 120 & 139 & 162 \\
\hline
\end{tabular}

Source: Wise, Lepori, Ingenhoff, and Buhmann (2015); total for 22 units.

catching up of human resources with the rapid increase of student numbers in the previous years. We discuss below, in section 5, the evolution of individual units.

In this 5-year period, the amount of third-party funds gained by these units also increased by $15 \%$, but with variations, explained by the life cycles of larger research contracts. Here, however, a shift has taken place: While the amount of competitive research funds (mostly from the Swiss National Science Foundation - SNSF) has increased by $73 \%$, contract funds have decreased by $41 \%$. This change is essentially due to two units, which were strongly oriented towards contract research and moved towards a more balanced composition of external funds. In 2009, third-party funds were equally divided between competitive and contract, while in 2013 three-quarters of funds were competitive, mostly from SNSF. This signals the establishment of MCS as a recognized academic discipline in the Swiss context, which is 
confirmed by the fact that from 2012 the main SNSF decision-making body also included a representative of the discipline.

Concerning publications, the evolution in the 5-year period showed some variation, with a decrease of $35 \%$ between 2009 and 2011 , followed by an increase of $42 \%$ by 2013 (see section 6 for more details).

The number of students enrolled at the bachelor's and master's level remained rather stable, as did the number of teaching hours. At the PhD level, however, the number of students (as well as graduates) increased by $35 \%$. An important increase is visible in the number of master's theses supervised by members of the research units, which nearly doubled in the 5-year window, reflecting the establishment of the Bologna model from the mid-2000s onwards.

So overall, after an important growth period from the mid-1990s to the mid-2000s, the field of MCS seems to have settled. The growth in student numbers was followed by a growth at the staff level, accompanied by a slight growth in funding and a more important growth in the number of $\mathrm{PhD}$ students (Wise et al., 2015). It remains to be understood what consequence the decrease in the student numbers from 2014 will have on the future evolution of the field.

\section{Topical diversity}

The field of Media and Communication Studies (MCS) is considered to be rather young in its institutionalization (Rogers, 1994; Meyen \& Löblich, 2006; Saxer, 2007), of an interdisciplinary character, influenced by a wide range of other fields (Schramm, 1983; Putnam, 2001; Wilke, 2016) and characterized by the presence of different sub-communities (O'Sullivan, 1999; Reardon \& Rogers, 1988; Rice, Borgman, \& Reeves, 1988; Leydesdorff \& Probst, 2009; Olivesi, 2006). This leads to a certain level of diversity in the field, which is confirmed also by recent meta-discussions (Corner, 2013; Couldry, 2013; Donsbach, 2006; Gray \& Lotz, 2013).
As specific studies on Switzerland have shown, the situation is similar to that discussed in the international community, with the heterogeneity even increased by the presence of three main national languages (Bonfadelli \& Bollinger, 1987; Lepori et al., 2011; Lepori et al., 2012). Research profiles of universities and research units cover a wide range of topics: mass communication, interpersonal communication, media history, language/social interaction, organizational communication and political communication, to give a few examples (see Probst \& Lepori, 2007). Besides topical diversity, the various units also differ regarding their mission, e.g., in teaching load or quantity of research.

The literature in sociology of science strongly suggests that cognitive and material practices of science are interrelated (Latour \& Woolgar, 1979; Becher \& Trowler, 2001), and that therefore differences in research topics correspond to systematic differences in the patterns of activities, outputs and resources.

To explore this relationship, we performed a cluster analysis based on the rating of the importance of different subject topics by the heads of the research units, focusing on the university sector (excluding universities of applied sciences). The analysis refers to the year 2009 for 21 units in universities.

This analysis yielded two clusters of units (see Buhmann et al., 2015). Classical fields of media and communication research (CMCR) is a cluster situated in the more traditional MCS topics such as mass communication, journalism studies or media audiences, reception and effects, referring to the classical theories of MCS. Emerging fields of media and communication research (EMCR) is a cluster of research units that are interested in more recently developed topics, such as intercultural communication, visual communication or health communication, also referring to a wide variety of concepts from other fields such as psychology, philosophy, language/rhetoric, business studies, and neurosciences. These two clusters are of rather similar size in terms of staff (67.4 
FTEs in CMCR vs 62.3 FTEs in EMCR) and they consist of 10 and 11 units respectively.

To explore the relationship between different topic profiles on the one hand and resources and activities on the other, we can further compare the two clusters on a variety of variables. Units within the two clusters differ in terms of the dimensions of activities and resources. Concerning the size in terms of staff and measured by the median of $\mathrm{FTE}^{2}$, EMCR units are slightly larger (median of 6.6 FTE) than CMCR units (5.1), which is explained mainly by a difference at the level of $\mathrm{PhD} /$ assistant positions (median of 3.7 vs 2.9 ).

Regarding funding, CMCR shows a higher total amount of funds (CHF 3.17 million vs CHF 2.46 million). However, roughly three-quarters of all funds are declared by only two units, therefore third-party funds are strongly concentrated. Furthermore, CMCR has a higher share of funds from private organizations.

Concerning publications, the CMCR cluster is more active than the EMCR cluster, while EMCR has a larger share of English-language publications (see section 6 below).

In terms of teaching activities, the CMCR cluster accounts for roughly $30 \%$ more teaching hours than EMCR. In both clusters, one unit is particularly active in teaching, accounting for approximately twice as many hours as the second unit in the cluster. A closer analysis, however, shows that a large share of the "additional" hours in CMCR is taught by external teachers, meaning that the internal teaching load is similar in the two clusters. At the MA level, however, the picture changes: EMCR organizes a higher number of teaching hours than CMCR, but also includes more external lecturers. Concerning supervised

2 Medians are preferred for unit-level comparisons given that distributions tend to be skewed and, therefore, averages might reflect the contribution of few units. Further, these differences are not statistically significant and don't allow for implications in terms of the relationship between cognitive and material practices of science, as suggested by Latour and Woolgar (1979) and Becher and Trowler (2001). theses, CMCR show higher numbers both at bachelor's and master's level.

Finally, we highlight major differences in terms of institutionalization. Most ECMR units are located in Lugano and St. Gallen, more than half of the professors are from abroad and have (at the PhD level) originally trained outside the communication field. By contrast, most CMCR units are in the German-speaking region, with professors mostly from the same region and trained within the field itself.

\section{Change at the level of individual units}

In this section, we go deeper into differences in activity profiles between individual units; and further, we investigate to what extent such differences are stable over time. Data for this analysis refers to the period 2009-2013.

To analyze differences between units regarding their orientation to education vs research, we run a factor analysis using four indicators of educational activities (teaching hours and number of theses for both the bachelor's and master's level) and five measures of research activity (total publications, $\mathrm{PhD}$ students and graduates, funds from funding agencies and contracts; Lepori et al., 2016).

This analysis identifies two main factors, which can be interpreted as a measure of research orientation and a measure of educational orientation.

The first factor, explaining $47 \%$ of the total variance, loads on PhD students and graduates, publications, research agency funds, contract funds and teaching hours at the master's level. The second factor (accounting for $23 \%$ of the variance) loads on teaching hours both at the bachelor's and master's level, on bachelor's and master's theses and on PhD students. Master's and $\mathrm{PhD}$ students load on both factors, showing their bridging function between the two pillars of higher education, underlying the intersection of research and teaching at these educational levels - and hinting, for PhDs, at the potential "double burden" 
Figure 2: Research units' educational and research orientation

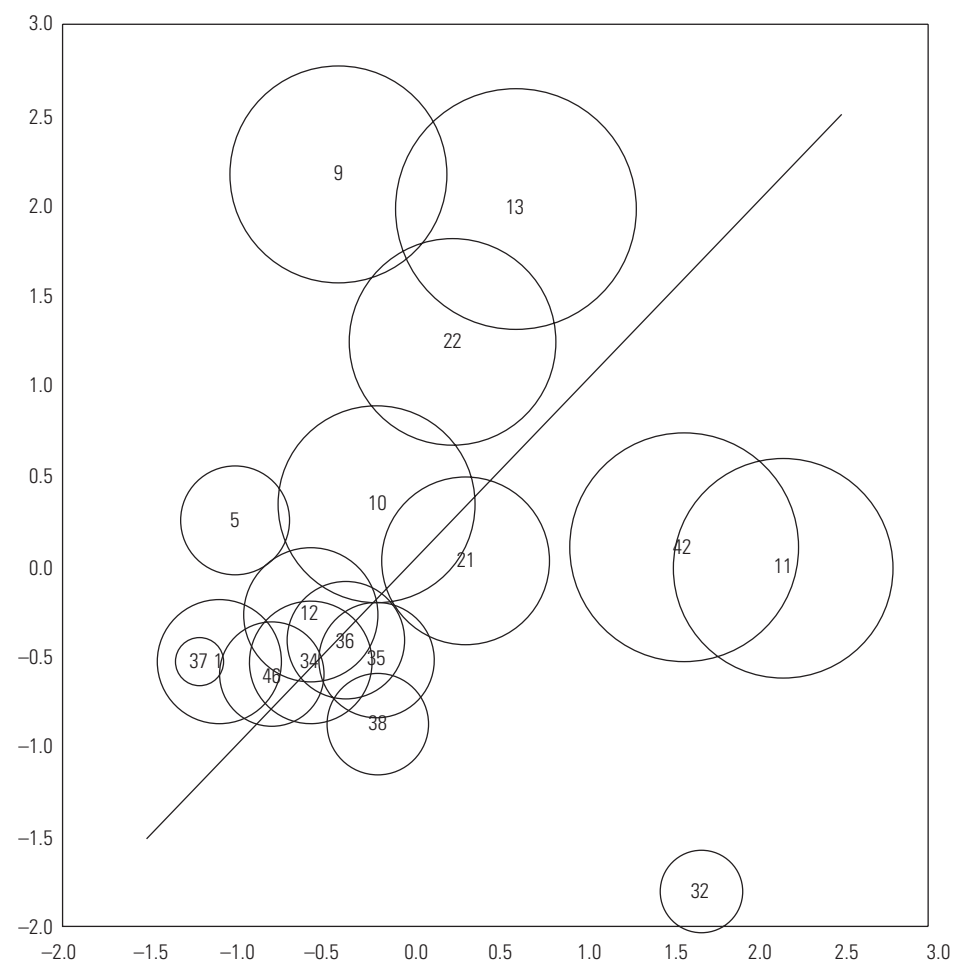

Note: Averages of the years in which the unit existed. The two axes are normalized scores for each unit for the two factors identified, i. e. a score $=1$ is equal to the average of the whole sample. Bubble size is proportional to full staff; numbers are units' IDs. Units above the diagonal line are more specialized towards research (relative to the field's average), units below the line are more specialized towards education (see Lepori, Wise, Ingenhoff, \& Buhmann, 2016).

at this career stage (see also the discussion on careers in section 7).

As illustrated by Figure 2, most units display a weak relative specialization, i.e. their balance between research and education is similar to the field's average, hinting at an environment that does not foster specialization. Three units are oriented more strongly towards education, and three towards research. Interestingly, five out of these six specialized units are located in the same university, probably indicating an environment that allows for more differentiation.

Further, it is interesting to see whether differences between units are stable over time. Since our data only cover the period 2009-2013, this analysis is mostly illustra- tive of a method that should be replicated over a longer time frame.

Results show a pattern differentiated by the activity considered and that changes in the overall field's activities are largely due to a few units. Regarding the number of total staff, one unit alone accounted for one-third of the total increase, while most of the total increase in professorial FTEs was concentrated in a single unit, which received four additional professors. As expected, those (larger) units that are organized as institutes (more than one professor, a larger number of total FTE) show more variation in their composition than units organized as chairs (one professor with a few junior researchers). 
Table 3: Publications, full sample, 2009-2013

\begin{tabular}{|c|c|c|c|c|c|c|}
\hline & 2009 & 2010 & 2011 & 2012 & 2013 & $\begin{array}{c}\text { Changes } \\
\text { 2009-2013 }\end{array}$ \\
\hline Total publications & 231 & 161 & 151 & 182 & 215 & $-7 \%$ \\
\hline Journal publications & 101 & 75 & 73 & 94 & 80 & $-21 \%$ \\
\hline Books & 38 & 17 & 9 & 7 & 12 & $-68 \%$ \\
\hline Book chapters & 80 & 61 & 62 & 75 & 117 & $+46 \%$ \\
\hline Publications in English & 135 & 90 & 79 & 109 & 108 & $-20 \%$ \\
\hline Journal publications in Scimago & 56 & 44 & 41 & 51 & 45 & $-20 \%$ \\
\hline Journal publications in first quartile & 19 & 10 & 18 & 34 & 29 & $+53 \%$ \\
\hline
\end{tabular}

Source: Wise, Lepori, Ingenhoff, and Buhmann (2015)

As for activities, differences between units (and absolute values) are quite stable for teaching at the bachelor's level, while substantial variation is observed at the master's level. Research agency and contract funds show an even higher variation; these funds are heavily concentrated in a few units and display important fluctuations between years.

This analysis therefore shows substantial differences between units within a field and differentiated patterns of evolution. Short-term variance in the units' activities is found mainly with regards to teaching at the master's level and project funding. Teaching at the bachelor's level is more stable and, therefore, constitutes the basis on which the units build their other activities. Finally, our analysis emphasizes that professorial positions are the critical resource for a unit's development and that this resource is mainly controlled by departments or faculties largely based on teaching activities (see Lepori et al., 2016).

\section{Publication cultures}

Publications represent the most tangible way in which outputs of research activities are made available to a broader audience. Beside their content, they can also be seen as giving indications on the network of the researchers, their geographical area of activity, or their type of audience.

In many fields of science, recent decades have seen a pressure towards more English language international publications (for a critical discussion in the field of MCS, see for example, Hanitzsch, 2016). Journal publications have become the gold standard, with a particular focus on journals contained and ranked in large databases, such as Scopus or Web of Science. However, in social science and humanities different publication cultures can be identified (Hicks, 2004), including an important role of book publication and of national languages. It is largely an open question whether convergence to a model oriented towards journals can be observed and is suitable to these disciplines.

These trends can also be observed in Swiss MCS. Table 3 shows the publication activity of the units considered for the years 2009-2013, including different types and characteristics of publications. This table is based on publicly available sources. Only the publications of people with an employment of at least $20 \%$ at the research unit were included in the sample, and no fractional counting for multi-authored publications was applied. The decline after 2009 is explained by methodological reasons. While in the first phase of the project, up to the year 2009, publication lists were provided by the individuals through a survey, the second phase did not use a survey and therefore relied on public sources, university databases, Google Scholar and CVs. From 2010 on, the data show a steady increase in the number of publications in general, while the proportion of publications written in English remained stable and the share of publications covered by Scimago, an international scientific database, tended to decrease. However, these trends should not be overinterpreted giv- 
Figure 3: Composition of publications by groups of units, 2009-2013

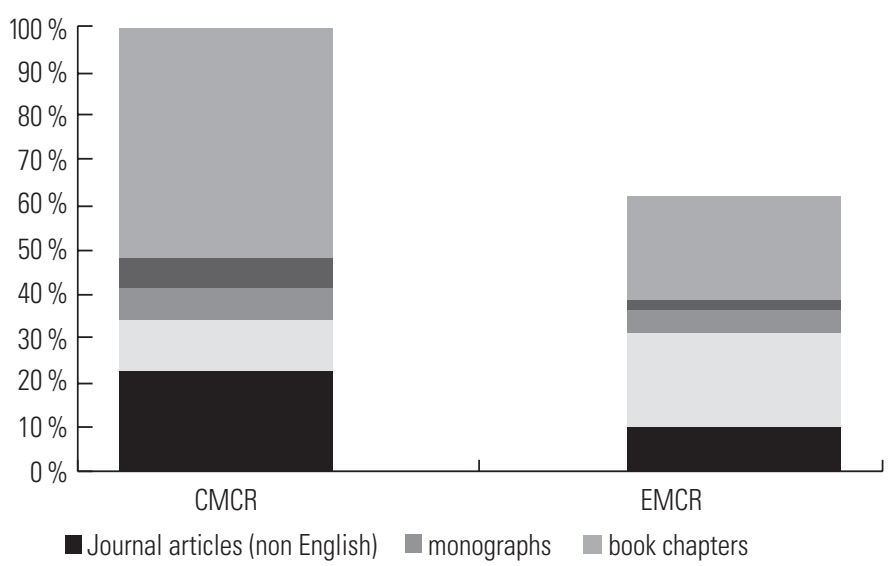

Note: Note. CMCR: Units in the cluster of Classical Media and Communication Research. EMCR: Units in the cluster of Emerging Media and Communication Research.

en the small numbers and the short timeframe considered.

The analyses show an average productivity per person at the professorial / senior level of 4 peer-reviewed journal articles, 6 book chapters, 10 conference presentations and 1 monograph in the 5-year period 2005-2009 (see Lepori et al., 2011). However, this productivity is mainly generated by a small number of individuals: Out of a group of 74 professors, senior researchers and post-docs who actively publish, 14 individuals account for more than half of the total output. The scientific production of the field is thus strongly dependent on a small number of highly productive individuals. These individuals are distributed quite evenly between the units, as only one unit includes more than one individual with more than 30 entries in its publication list for the 5-year period.

English is the most frequent language of publication for journal articles and presentations to scientific conferences, while national languages prevail for all other types of publication (see, for example, Lepori et al., 2011). Roughly $20 \%$ of monographs, edited books, and book chapters are published in Switzerland, and slightly more than $20 \%$ of all conference presentations take place in Switzerland, while more than $45 \%$ of all conference presentations are held at conferences in countries where none of the national languages of Switzerland is a national language (see Wise et al., 2015).

Journal publications reveal a broad scope (results from data 2005-2009, see Lepori et al., 2011): 571 entries are spread among 330 different journals, reflecting the diversity of the field. Only in 76 journals were more than one article published in the 5-year period, while only 17 journals account for more than 5 articles. By far the highest number of publications in a journal is found in "Studies in Communication Sciences", edited by the SACMR together with the University of Lugano (45 entries), followed by "Zeitschrift für Organisations-Entwicklung» (15), «Medienwissenschaft Schweiz» (12 - one of the two journals that merged into Studies in Communication Sciences in 2007), "Klartext» (10) and «Publizistik» (10). Regarding book publications, ten publishing houses published nearly half (338) of all (682) book publications, with large German publishing houses at the top (VS Verlag für Sozialwissenschaften, UVK Verlagsgesellschaft, Herbert von Halem Verlag, Haupt Verlag, and Springer Verlag each accounting for more than 30 publications).

A closer look highlights large differences between units that are associated with their topic orientation (Figure 3). CMCR units still largely publish in national lan- 
Figure 4: Mobility in Swiss MCS

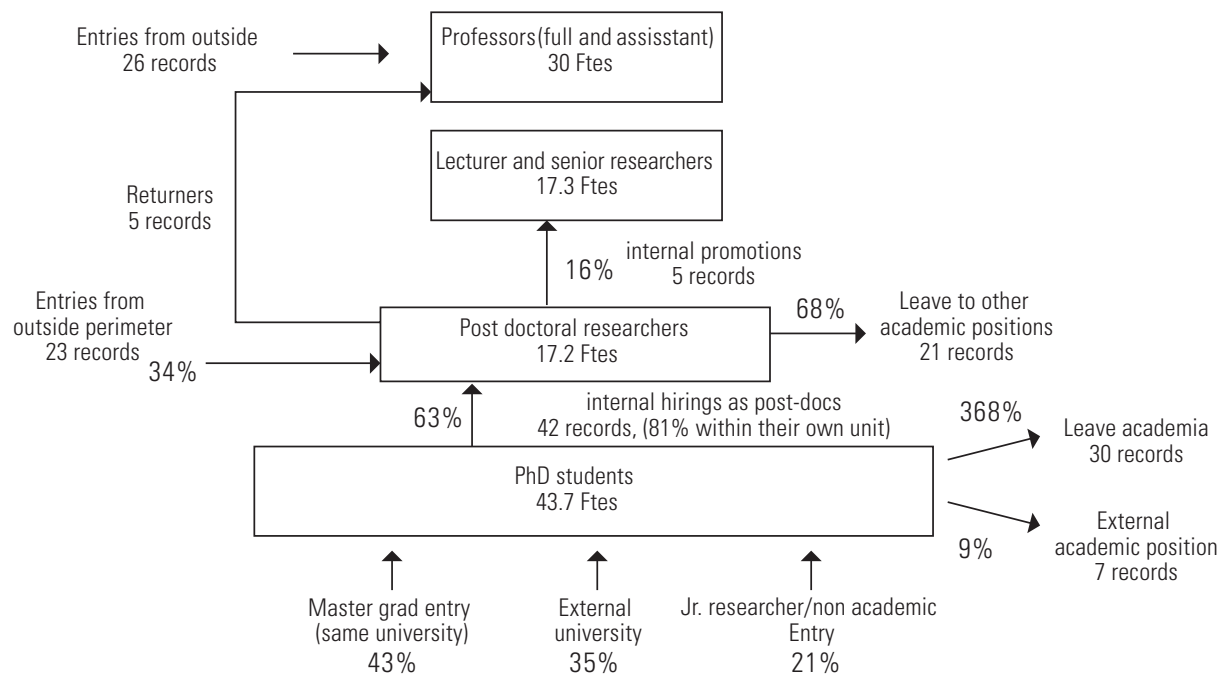

guages, notably German (with only $26 \%$ of the publications in English), while EMCR units mostly publish in English (58\%). For EMCR units English journal papers represent the main type of publication media, while books and book chapters are the main outlet for CMCR units (alongside non-English journal publication, mostly German communication journals; Buhmann et al., 2015). As known from previous studies of communication research, differences in publication culture correspond to different topic and geographic orientation towards the German vs. the Anglo-Saxon world (see, for example, Lauf, 2001). However, at the same time, some practices are common to the whole field, like an important share of book publications, while in the CMCR English journal papers are also gaining in importance.

The analysis of the publication output could be extended in the future in several directions. On the one hand, the analysis of co-authorship would provide important insight into the collaboration patterns of the field and its (different) geographical orientations (Glänzel \& Schubert, 2005). On the other hand, co-word analysis could provide more fine-grained insights on research topics and their evolution over time (Van den Besselaar \& Heimeriks, 2006).

\section{Mobility and career pathways}

In the second project phase, we have undertaken a detailed analysis of the career paths of the people in the field. This analysis is relevant for different issues: to investigate the linguistic and cultural connections to neighbours, as revealed by the flow of people, particularly at the professorial level (Probst \& Lepori, 2007; Lepori \& Probst, 2009); to analyze to what extent changes in the structure of academic careers revealed by international (Enders \& Musselin, 2008) and Swiss (Fumasoli \& Goastellec, 2015) studies have also affected the MCS field; and to provide some empirical evidence to the ongoing debate on academic careers in Switzerland and complaints about the lack of stable positions for young researchers (SBFI, 2014). For each individual, the dataset systematically records all entry and exit events to units in the field, as well as instances of vertical mobility within the same unit (for example $\mathrm{PhD}$ students being hired as post-docs).

More than half of the 101 individuals identified in 2009 were still in the same research unit in 2013. Some had been promoted internally (mostly from $\mathrm{PhD}$ student to post-doc), while others remained in the same position. None of the 44 junior 
researchers remained in the same position, however, with 18 of them appointed to a new function within their unit. Changes between research units in the same university are noted in only 3 cases - one professor and two junior researchers - and changes within the perimeter of analysis (i.e., those 22 research units included in our study) are also not frequent. Only 4 junior researchers left for a unit at another university, while 15 individuals left for units outside the perimeter of analysis ( 2 professors, 9 seniors and 4 junior researchers), and 6 junior researchers left for a non-academic job. Additionally, $6 \mathrm{PhD}$ students left before completion of their PhD. Finally, 4 professors retired.

When analysing the whole sample, and not only the 2009 cohort as above, a broader picture is possible, with the limitation that two thirds of the individuals have been members of the research units for 4 years or less. Hence, the extent of stability might be overestimated.

Among these 322 individuals, 178 remained in the same position, while 46 changed their position within the same unit. Among the others, the distribution of exit "destinations" is rather similar in the whole sample as in the 2009 cohort, with small exceptions: The share of uncompleted $\mathrm{PhDs}$ is $50 \%$ higher in the overall cohort (20 out of 98 individuals leaving the research unit as compared to 6 out of 45), while - as can be expected - the share of retirements is higher in the 2009 cohort than in the overall cohort (as only 1 person who started working in a research unit after 2009 had already retired by 2013).

A total of 33 individuals left their unit for another academic unit, with 9 of them remaining in Switzerland and the others leaving for the United Kingdom (7), Italy (6), Germany (5), the United States (2), Sweden (2), and other countries (2).

Overall, the sample contains 316 entry events, with more than half of them being at the junior level (169) compared to 97 at senior level and 50 at professorial level.

Of the 50 entries at the professorial level 26 are from an academic unit outside the perimeter. Only two of these individuals were working in Switzerland before, while the others came from Germany (10), Italy (6), the US (3), the UK (2), and other countries (3), thereby showing the strong prevalence of entries from the linguistic region of the hiring university. Ten entries occurred from other research units in the perimeter ( 9 of them being promotions to the professorial level, as only 1 exit of a professor to another unit in the perimeter is registered). In only 5 cases did internal promotion occur, while in 8 cases the entry event could not be accounted for in the data collection.

At the senior level, a large share (43 out of 97) of all entries were internal promotions, while 4 individuals entered from another unit in the perimeter. The 30 entries from outside the perimeter of the study also show the pattern of the linguistic region: Italy (12) and Germany (7) are the most important countries of origin, while 5 entries were from within Switzerland. Furthermore, 2 entries are registered from the US and the UK respectively, and 2 from other countries. At this level, 2 entries from a non-academic position also occurred during the period of study, while in 9 cases the entry event could not be accounted for.

The picture differs strongly at the junior level. As might be expected, a large share of all entries (125 out of 169) are from the master's level. These entries usually occur from the same university (73) or from a university abroad (44), while it is clearly uncommon that a master's graduate from one Swiss university is employed at the junior level at another Swiss university (8 individuals). This might be explained by linguistic barriers, but also by a pattern where professors identify among their master's students promising $\mathrm{PhD}$ candidates and hire them directly without an open call. However, there are also a few entries from other academic units (6 in the same department, 2 within the perimeter, 13 outside the perimeter), changes of function within the unit (8) and 10 entries from non-academic positions. In 5 cases, no information was available.

Figure 4 summarizes the mobility patterns in Swiss MCS in the 5-year period from 2009 to 2013. It shows a clear divide 
between the professorial level and that of young researchers. At the top level of the academic hierarchy, hiring is clearly international with a focus on linguistic neighbours as well as the US and UK - chances to become a professor for local people being very limited, unless they have been abroad for a period ('returners'). On the contrary, the $\mathrm{PhD}$ and post-doc level are characterized by a large degree of 'inbreeding' (Horta, Veloso, \& Grediaga, 2010), where most PhDs are hired within the same unit for a first post-doctoral period. This is, however, a transitory situation, with most of these people moving to other academic positions or leaving academia within a 4 -year period. Between the two, we could identify a small group of 'survivors' who managed to stay long-term in the same university in positions like lecturer and senior researcher, but with almost no chance to get to a professorial position (see Buhmann et al., 2017).

\section{Conclusions}

With this analysis of the overall evolution, topic diversity, publications, careers and changes at the level of individual units, we have given a broad picture of the field of MCS in Switzerland over the last decade. This picture can be helpful for established researchers to better understand their scientific environment, as well as for young researchers to learn more about the expectations towards them with respect to their career and to evaluate their own career options. The analyses show that the field as a whole has reached a consolidation phase, with rather stable personnel structures (i.e., resources) and teaching activities at the bachelor's level. Other resources, i.e., funding, show some variation, as do teaching activities at the master's level. Also, at the level of individual units, more variation throughout the years is visible. However, in the overall profiles, the units are mostly rather stable.

It can be said, therefore, that the field is currently in a rather stable, consolidated situation. This is also reflected in its resources, which are unlikely to grow expo- nentially in the coming years. This means that we can expect future job opportunities to come only from replacing the former positions of retired professors rather than from new, additional positions being created. While job descriptions in many of the classical as well as the emerging fields of communication might be aligned to the new challenges of digitalization, the total number of positions is expected to remain stable.

At the same time, however, the field also faces various challenges, with factors influencing both the academic profession and the professionals in the field of MCS studies and teaching. The most prominent factor might be digitalization, which is likely to have an impact on both areas. This can already be observed in the current discussion in the German-speaking region, where the question of the field's identity is seeing a revival (see for example Wilke, 2016; Hepp, 2016; Jarren, 2016; Theis-Berglmair, 2016), with discussions about the subject that the field is concerned with being of central importance. Communities that were formerly separated as studying mass and individual communication might find common ground, including increasingly through research funding, new teaching modules and courses in the area of digitalization. This process might produce some tension: Wilke (2016), for example, pictures the history of the field of MCS as an integrating field of science (Integrationswissenschaft) and points to the differentiation process that has taken place over recent decades. He warns that this differentiation might lead to disintegration and asks whether a common ground in the field still exists. It seems possible that this common ground is currently being reshaped.

Digitalization, however, also has its influences on academic life. The way we learn, teach, collaborate and do research is challenged; new tools might imply a new culture. For young scholars, it is essential to be familiar with new methods and approaches in order to cope with big data, datafication and automated learning tools. This might additionally promote a change in traditional separations in the 
field, allowing for new collaborations, but also collaboration cultures, to emerge. It seems likely that some changes in existing structures - both in terms of organization and curricula - might occur, and that new units combining subjects that were hitherto separated might emerge.

A further challenge for the field is a certain pressure towards homogenization: international norms and values concerning the conduct of research are increasingly gaining ground, visible for example in performance agreements fixing performance measures (also described in the general trend of "new public management"), in the urgency to increase one's publication output (see, for example, Hanitzsch, 2016), especially in the English language and in international outlets, or in the fact that international mobility is becoming more and more a precondition for an academic career. This creates tensions with respect to traditional links to Swiss society and cultures(s) that will have to be managed carefully.

Coming back to our initial RQs, our results demonstrate the growing number of English journal publications, which also mirrors the growing pressure towards more publication in international journals, especially for young tenured scholars. As a consequence, many young $\mathrm{PhD}$ students now aim at writing a paper dissertation, comprising 3-4 empirical journal papers and a summary article. At the same time, this tendency also raises lots of concerns and discussions within the community (see, for example, DGPuK, 2017) that point at a potential future loss of theory development and deeper understanding of the overall field of communication science. However, "countermovements" become visible as well: we also observe a strong recognition of the need to evaluate the quality and not only the quantity and impact factors of journal articles. Many Swiss universities, as well as the Swiss National Foundation, have already signed the so-called DORA principles ("San Francisco Declaration on Research Assessment") ${ }^{3}$, in which comprehensive assessments away

3 https://sfdora.org (21.02.2019) from journal-based metrics like Journal Impact Factors are recommended, and institutions are asked to "consider the value and impact of all research outputs (including datasets and software) in addition to research publications, and consider a broad range of impact measures including qualitative indicators of research impact, such as influence on policy and practice"4. Our approach and instrument presented in this paper, encouraging the measurement of research units and researchers through their various activities like scientific production (also comprising community recognition and research training), education and transfer activities as well as resources, might be one fruitful approach to support such a comprehensive assessment.

Hence, it remains important to continue observing the field of MCS in the future. The picture we have given in our study provides useful information and important indicators for further analyses of the field.

\section{References}

Altmeppen, K., Weigel, J., \& Gebhard, F. (2011). Forschungslandschaft Kommunikationsund Medienwissenschaft. Publizistik, 56(4), 373-398. doi:10.1007/s11616-0110132-7

Becher, T. \& Trowler, P. R. (2001). Academic tribes and territories. Intellectual enquiry and the culture of disciplines. Ballmoor, UK \& Philadelphia, PA: The Society for Research into Higher Education and Open University Press.

Bonfadelli, H. \& Bollinger, E. (1987). Entwicklungen und Stand der Publizistikwissenschaft in der Schweiz. In F. H. Fleck, U. Saxer, \& M.F. Steinmann (Eds.), Massenmedien und Kommunikationswissenschaft in der Schweiz. Jubiläumsschrift der SGKM (pp. 3-17). Zurich, CH: Schulthess Polygraphischer Verlag.

Bonfadelli, H. (2007). Publizistikwissenschaft und Medienforschung: Berufsfelder mit Perspektive. In M. Marr (Ed.), Kommu-

4 https://sfdora.org/read/(Dora-Principles Point 5) 
nikationsallrounder für die Mediengesellschaft Schweiz (pp. 81-85). Zürich: vdf Hochschulverlag AG.

Braam, R., \& van den Besselaar, P. (2010). Life cycles of research groups: The case of CWTS. Research Evaluation, 19(3), 17-18. doi:10.3152/095820210X503465

Buhmann, A., Ingenhoff, D., \& Lepori, B. (2015). Dimensions of diversity: Mapping the field of media and communication studies by combining cognitive and material dimensions. European Journal of Communication Research, 40(3), 267-293. doi:10.1515/ commun-2015-0010

Buhmann, A., Lepori, B., \& Ingenhoff, D. (2017, August). Clashing conventions: Exploring human resource management in the cleavage between local orders and global standards. Paper presented at the Annual Conference of the Consortium of Higher Education Researchers (CHER), Jyväskylä, Finland.

Corner, J. (2013). Is there a 'field' of media research? - The 'fragmentation' issue revisited. Media, Culture \& Society, 35(8), 10111018. doi:10.1177/0163443713508702

Couldry, N. (2013). If not a single field, then what? Media, Culture \& Society, 35(8), 1023-1026. doi:10.1177/0163443713508704

DGPuK (2017). Debatte: Promotionsverfahren in der Kommunikationswissenschaft. Aviso, 64. URL: https://www.dgpuk.de/sites/ default/files/Aviso_64_01-20171.pdf

Donsbach, W. (2006). The identity of communication research. Journal of Communication, 56(3), 437-448. doi:10.1111/j.14602466.2006.00294.x

Enders, J. \& Musselin, C. (2008). Back to the future? The academic professions in the $21^{\text {st }}$ century. In OECD (Ed.), Higher Education to 2030, Volume 1, Demography (pp. 125-150). Paris: OECD Publishing.

Fumasoli, T., \& Goastellec, G. (2015). Recruitment of academics in Switzerland: E pluribus unum? In U. Teichler \& W. Cummings (Eds), Forming, Recruiting and Managing the Academic Profession (pp.145-161). Cham, CH: Springer. doi:10.1007/978-3319-16080-1_8

Glänzel, W., \& Schubert, A. (2005). Analysing scientific networks through co-authorship. In H. F. Moed, W. Glänzel, \& U. Schmoch (Eds.), Handbook of quantitative science and technology research (pp. 257-276). Dordrecht, NL: Kluwer Academic Publications. doi:10.1007/1-4020-2755-9_12

Gray, J., \& Lotz, A. D. (2013). A robust and dynamic field. Media, Culture \& Society, 35(8), 1019-1022. doi:10.1177/0163443713508703

Gysin, N., Meier, P., Blum, R., Häussler, T., \& Süss, D. (2004). Evaluation der Koтmunikations- und Medienwissenschaft in der Schweiz. Selbstevaluationsbericht. Bern.

Hanitzsch, T. (2016). Impact und Normalwissenschaft. Die Fachzeitschrift als Treiber einer neuen Wissenschaftskultur - ein Zwischenruf. Publizistik, 61(1), 41-50. doi:10.1007/s11616-015-0250-8

Hepp, A. (2016). Kommunikations- und Medienwissenschaft in datengetriebenen Zeiten. Publizistik, 61(3), 225-246. doi:10.1007/s11616-016-0263-y

Hessels, L. K. \& Freeman, J. (2010). Science and the struggle for relevance. Oisterwijk, NL: Uitgeverij BOXPress.

Hicks, D. (2004). The four literatures of social science. In H. F. Moed, W. Glänzel, \& U. Schmoch (Eds.), Handbook of quantitative science and technology research (pp. 473496). Dordrecht, NL: Kluwer Academic Publishers. doi:10.1007/1-4020-2755-9_22

Hicks, D., Wouters, P., Waltman, L., De Rijcke, S., \& Rafols, I. (2015). Bibliometrics: The Leiden Manifesto for research metrics. Nature, 520, 429-431.

Horta, H., Veloso, F., \& Grediaga, R. (2010). Navel gazing: Academic inbreeding and scientific productivity. Management Science, 56(3), 414-429. doi:10.1287/ mnsc.1090.1109

Jarren, O. (2016). Nicht Daten, sondern Institutionen fordern die Publizistik- und Kommunikationswissenschaft heraus. Publizistik, 61(4), 373-383. doi:10.1007/ s11616-016-0301-9

Latour, B., \& Woolgar, S. (1979). Laboratory life. The construction of scientific facts. Princeton, NJ: Princeton University Press.

Lauf, E. (2001). “Publish or perish?” Deutsche Kommunikationsforschung in internationalen Fachzeitschriften. Publizistik, 46(4), 369-382. doi:10.1007/s11616-001-0119-x

Larédo, P., \& Mustar, P. (2000). Laboratory activity profiles: An exploratory ap- 
proach. Scientometrics, 47(3), 515-539. doi:10.1023/A:1005671901143

Lepori, B. (2008). Research in non-university higher education institutions. The case of the Swiss Universities of Applied Sciences. Higher Education, 56(1), 45-58. doi:10.1007/s10734-007-9088-y

Lepori, B., Wise, M., Ingenhoff, D., \& Buhmann, A. (2016). The dynamics of university units as a multi-level process. Credibility cycles and resource dependencies. Scientometrics, 109(3), 2279-2301. doi:10.1007/ s11192-016-2080-5

Lepori, B., \& Probst, C. (2009). Using curriculum vitae for mapping scientific fields. A smallscale experience for Swiss communication sciences. $R e$ search Evaluation, 18(2), 125-134. doi:10.3152/095820209X441772

Lepori, B., Ingenhoff, D., Probst, C., Donzallaz, D., Hove, I., \& Bähni, A. (2011). Measuring research output in communication sciences and educational sciences between international benchmarks, cultural differences and social relevance. Project report. Lugano \& Fribourg, $\mathrm{CH}$.

Lepori, B., Probst, C., \& Ingenhoff, D. (2012). Profile statt Rankings: Eine Methode zur Darstellung von Aktivitäten institutioneller Einheiten der Kommunikationswissenschaft. Medien \& Kommunikationswissenschaft, 60(1), 80-101. doi:10.5771/1615634x-2012-1-80

Leydesdorff, L., \& Probst,C. (2009). The delineation of an interdisciplinary specialty in terms of a journal set: The case of communication studies. Journal of the American Society for Information Science and Technology, 60(8), 1709-1718. doi:10.1002/ asi.21052

Meier, P., \& Blum, R. (2004) Im schweizerischen Erdreich verwurzelte Wissenschaft. Zur Fachgeschichte der Journalistik und Zeitungskunde in der Schweiz vor 1945. In W. Duchkowitsch, F. Hausjell \& B. Semrad (Hrsg.), Die Spirale des Schweigens. Zum Umgang mit der nationalsozialistischen Zeitungswissenschaft (pp. 167177). Münster: LIT Verlag.

Meyen, M. and Löblich, M. (2006). Klassiker der Kommunikationswissenschaft. Fach- und Theoriegeschichte in Deutschland. Konstanz, GE: UVK.
O'Sullivan, P. (1999). Bridging the mass-interpersonal divide. Synthesis Scholarship in HCR. Human Communication Research, 25(4), 569-588. doi:10.1111/j.1468-2958.1999.tb00462.x

Olivesi, S., (Ed.) (2006). Sciences de l'Information et de la Communication. Objets, savoirs, discipline. Grenoble, FR: Presses universitaires de Grenoble.

Probst, C., Lepori, B., \& Ingenhoff, D. (2010). Mehrdimensionale Profile von Forschungsgruppen: Ein Vorschlag für die Erhebung von Forschungsleistung in der Kommunikationswissenschaften. Qualität in der Wissenschaft, 4, 98-105.

Probst, C., \& Lepori, B. (2007). Für eine Kartographie der Schweizer Kommunikationswissenschaften. Studies in Communication Sciences, 7(1), 253-270. doi:10.5169/ seals-791076

Probst, C., Lepori, B., De Filippo, D., \& Ingenhoff, D. (2011) Profiles and beyond: Constructing consensus on measuring research output in communication sciences. Research Evaluation, 20(1), 73-88. doi:1 0.3152/095820211X12941371876102

Putnam, L. L. (2001). Shifting voices, oppositional discourse, and new visions for communication. Journal of Communication, 51(1), 38-51. doi:10.1111/j.1460-2466.2001. tb02871.x

Reardon, K. K., \& Rogers, E. M. (1988). Interpersonal versus mass media communication. A false dichotomy. Human Communication Research, 15(2), 284-303. doi:10.1111/j.1468-2958.1988.tb00185.x

Rice, R. L., Borgman, C. \& Reeves, B. (1988). Citation networks of communication journals, 1977-1985. Cliques and positions, citations made and citations received. Human Communication Research, 15(2), 256-283. doi:10.1111/j.1468-2958.1988. tb00184.x

Rogers, E. M. (1994). A history of communication study. A biographical approach. New York: The Free Press.

Saxer, U. (2007). Schweizerische Kommunikationswissenschaft: Transdisziplinär? Studies in Communication Sciences, 7(1), 231-252. doi:10.5169/seals-791075

Schade, E. (Ed.) (2005). Publizistikwissenschaft und öffentliche Kommunikation. Beiträge 
zur Reflexion der Fachgeschichte. Konstanz, GE: UVK.

Schmoch, U., Schubert, T., Jansen, D., Heidler, R., \& von Görtz R. (2010). How to use indicators to measure scientific performance: A balanced approach. Research Evaluation, 19(1), 2-18. doi:10.3152/095820210X492477

Schramm, W. (1983). The unique perspective of communication: A retrospective view. Journal of Communication, 33(3), 6-17. doi:10.1111/j.1460-2466.1983.tb02401.x

Staatssekretariat für Bildung, Forschung und Innovation SBFI (2014). Massnahmen zur Förderung des wissenschaftlichen Nachwuchses in der Schweiz. Bericht des Bundesrats in Erfüllung des Postulats WBK-SR (12.3343). Bern, CH.

Süss, D. (2000). Institutionelle Strukturen und Ausbildungssituation. Kommunikationsund Medienwissenschaft in der Schweiz. Medien Journal, Zeitschrift für Kommunikationskultur, 2, 19-27.

Theis-Berglmair, A. M. (2016). Auf dem Weg zu einer Kommunikationswissenschaft. Publizistik, 61(4), 385-391. doi:10.1007/ s11616-016-0302-8

Van den Besselaar, P., \& Heimeriks, G. (2006). Mapping research topics using word-reference co-occurrences: A method and an exploratory case study. Scientometrics, 68(3), 377-393. doi:10.1007/s11192-006-0118-9

Van Vught F. (2009). Mapping the higher education landscape. Towards a European classification of higher education. Milton Keynes, UK: Springer.

Wilke, J. (2016). Von der Zeitungskunde zur Integrationswissenschaft. Medien \& Kommunikationswissenschaft, 64(1), 74-92. doi:10.5771/1615-634X-2016-1-74

Wise, M., Lepori, B., Ingenhoff, D., \& Buhmann, A. (2015). Evolution of the field of communication science in Switzerland. Research Report. Lugano \& Fribourg. $\mathrm{CH}$ 
